\title{
Bases Genéticas y Moleculares del COVID-19 (SARS-CoV-2). Mecanismos de Patogénesis y de Respuesta Inmune
}

\author{
Genetic and Molecular Basis of COVID-19 (SARS-CoV-2) \\ Mechanisms of Pathogenesis and Imnune
}

\author{
Gabriel Pastrian Soto
}

\begin{abstract}
PASTRIAN, S. G. Bases genéticas y moleculares del COVID-19 (SARS-CoV-2). Mecanismos de patogénesis y de respuesta inmune. Int. J. Odontostomat., 14(3):331-337, 2020.

RESUMEN: A fines de diciembre de 2019, un nuevo coronavirus (SARS-CoV-2) fue identificado como el agente causal de una nueva enfermedad respiratoria llamada COVID-19 por la OMS. Sus síntomas incluyen fiebre, tos seca y dificultad respiratoria. Estos síntomas en general son leves, aunque, pueden ser fatales en adultos mayores y pacientes con comorbilidades. Se realizó búsqueda bibliográfica en Pubmed y Clinical Key donde se seleccionaron 22 artículos de acuerdo con los criterios de inclusión. SARS-CoV-2 pertenece al género de los Betacoronavirus y tiene similitudes genómicas con SARS-CoV y MERS-CoV. El virión de SARS-CoV-2 consta de una nucleocápside y de una envoltura externa compuesta por proteínas estructurales principales y accesorias. Su material genético consiste en una cadena de RNA monocatenario de polaridad positiva, en el que, se codifican proteínas importantes para su transcripción y replicación. El mecanismo de infección de SARS-CoV-2 comienza con la unión del virión a un receptor (ACE2) de la célula huésped y su posterior entrada por endocitosis. El genoma RNA viral se libera al citoplasma donde se transcriben y se traducen las proteínas necesarias para la producción de las proteínas estructurales y para la replicación de su material genético. Posteriormente, el RNA replicado se asocia con la nucleocápside y se ensambla junto con las proteínas estructurales para conformar las partículas víricas que serán liberadas de la célula infectada. El sistema inmune hace frente a la infección viral mediante el reconocimiento de patrones moleculares asociados a patógenos (PAMPs) por parte de la inmunidad innata y por la acción de los linfocitos T y B por parte de la inmunidad humoral. El conocimiento de las bases genéticas y moleculares de SARS-CoV-2 permite visualizar la posibilidad de establecer tratamientos farmacológicos o desarrollo de vacunas para controlar y disminuir los efectos patogénicos de la enfermedad.
\end{abstract}

PALABRAS CLAVE: COVID-19, SARS-CoV-2, Genetica, Patogénesis, Respuesta inmune.

\section{INTRODUCCIÓN}

A fines de diciembre de 2019, los centros de salud locales en Wuhan, provincia de Hubei, China. Informaban sobre grupos de pacientes que presentaban una neumonía de etiología desconocida (Liu et al., 2020). Desde el principio, se advertía que estos grupos de pacientes estaban vinculados epidemiológicamente con un mercado mayorista de mariscos de la cuidad (Qingmei et al., 2020). Posteriormente, científicos chinos identificaron al agente causal como un nuevo coronavirus (CoV) y su secuencia genómica se hizo pública (Wuhan-Hu-1, GenBank Accession No. MN908947) (Dae-Gyun et al., 2020; Yan-Rong et al., 2020). La Organización Mundial de la Salud (OMS) anunció el nombre oficial de la nueva enfermedad como "enfermedad por coronavirus 2019" (COVID-19) (Yen-Rong et al.); y El Comité Internacional de Taxonomía de Virus lo nombró SARS-CoV-2 (Firas et al., 2020). Hasta el día de hoy, 27 de abril de 2020, La OMS ha reportado un total de 2.878.196 casos confirmados y un total de 198.668 fallecidos. En Chile se han reportado 13.331 casos confirmados y 189 fallecidos (World Health Organization, 2020).

\section{Alcances Clínicos de la Enfermedad de COVID-19}

Se ha evidenciado que SARS-CoV-2 es un virus altamente contagioso y transmisible entre los humanos (Mahdi et al., 2020). El ritmo básico de repro- 
ducción o número reproductivo básico (R0) da cuenta de la cantidad de personas que un huésped enfermo puede infectar. Si el R0 < 1, la enfermedad desaparece después de un periodo de tiempo, mientras que si el $\mathrm{R} 0>1$, la enfermedad se propaga entre las personas. Las OMS ha estimado que para SARS-CoV-2 existe un R0 que oscila entre 1.4 y 2.5 (Firas et al.). El principal modo de transmisión de la enfermedad es por medio de la inhalación de gotitas respiratorias desde una persona infectada a otra existiendo un contacto estrecho entre ambas (Eakachai et al., 2020). Según la epidemiología, el período de incubación del virus oscila entre 2 y 14 días, presentándose la aparición de síntomas aproximadamente al 5to día (Hussin \& Siddappa, 2020). Las características clínicas de COVID-19 son variadas, las que pueden manifestarse desde una infección asintomática hasta una neumonía leve a severa (Kannan et al., 2020). Los principales síntomas incluyen fiebre, tos seca, mialgia, fatiga y dificultad respiratoria; y en menor medida, diarrea, náuseas y vómitos (Liu et al.; Mahdi et al.). Generalmente, muchos de los pacientes presentan síntomas respiratorios leves (Xiaoyi et al., 2020). Sin embargo, los adultos mayores y pacientes con comorbilidades subyacentes, tales como, hipertensión, enfermedad pulmonar obstructiva crónica, diabetes y/o enfermedad cardiovascular, pueden desarrollar cuadros de mayor gravedad como síndrome de dificultad respiratoria aguda y shock séptico, los que, podrían conducir incluso a la muerte (Yan-Rong et al.). Respecto exámenes de laboratorio, se ha evidenciado que en la mayoría de los pacientes se presentan recuentos normales a disminuidos de glóbulos blancos y plaquetas, lo que podría indicar, presencia de linfocitopenia, trombocitopenia y leucopenia (Yan-Rong et al.; Liu et al.; Qingmei et al.). En un estudio en 1099 pacientes infectados con SARS-CoV-2 de diferentes provincias de China, se observó que la tasa de linfocitos estaba por debajo del rango normal en el $83,2 \%$ de los pacientes, la tasa de plaquetas estaba por debajo del rango normal en el 36,2\% y la tasa de leucocitos fue menor que el rango normal en el 33,7 \% de los casos (Mahdi et al.).

\section{MATERIAL Y MÉTODO}

Se realizó búsqueda bibliográfica en las bases de datos de Pubmed y Clinical Key con los términos "Pathogenesis [AND] COVID-19". Los criterios de inclusión fueron: Ensayos clínicos en humanos y reviews. Se hallaron un total de 101 artículos de los cuales se seleccionaron 22 de ellos.

\section{RESULTADOS}

\section{Taxonomía de SARS-CoV-2}

Los coronavirus (CoV) son unos patógenos importantes en humanos y vertebrados. Estos pueden infectar los sistemas respiratorio, gastrointestinal, hepático y nervioso central de humanos, ganado, aves, murciélagos, ratones y de muchos otros animales salvajes (Chen et al., 2020; Rokni et al., 2020). El primer CoV aislado correspondió al virus de la bronquitis infecciosa aviar en 1930 (Sin-Yee et al., 2020; Zi-Wei et al., 2020). Los CoV pertenecen a la subfamilia Coronavirinae, pertenecientes a la familia Coronaviridae del orden Nidovirales (Chen et al.). El orden Nidovirales incluye a los virus que usan un conjunto anidado de RNA mensajero (RNAm) para su replicación (Ali et al., 2020). Los CoV se pueden dividir genotípica y serológicamente en cuatro géneros: Alfacoronavirus, Betacoronavirus, Gammacoronavirus y Deltacoronavirus (Firas et al.; Chen et al.; Sin-Yee et al.; Yuefei et al., 2020). Los Alfacoronavirus y Betacoronavirus infectan a los mamíferos, mientras que, los Gammacoronavirus y Deltacoronavirus tienden a infectar a las aves, aunque, también algunos de ellos pueden transmitirse a los mamíferos (Mahdi et al.). Basado en las relaciones filogenéticas y estructuras genómicas, SARS-CoV-2 pertenece al género de los Betacoronavirus (Mousavizadeh \& Ghasemi, 2020).

\section{Infecciones de CoV en Humanos}

SARS-CoV-2 no es el primer brote de enfermedad respiratoria grave que es causado por un $\mathrm{CoV}$ ( $\mathrm{Li}$ et al., 2020a,b). Antes de SARS-CoV-2, se conocían otros seis CoV causantes de enfermedades en humanos. Estos se pueden dividir de acuerdo con el grado de patogenicidad que provocan, es decir, como virus poco o altamente patógenos. Los CoV de baja patogenicidad corresponden a 229E, HKU1, OC43 y NL63, los que representan entre un $10 \%$ y un $30 \%$ de las infecciones del tracto respiratorio superior y que, por lo general, causan enfermedades respiratorias leves. Por el contrario, los CoV altamente patógenos corresponden al Síndrome Respiratorio Agudo Severo (SARS-CoV) y al Síndrome Respiratorio Medio Oriente (MERS-CoV), los cuales, infectan predominantemente las vías respiratorias inferiores y pueden causar neumonía fatal (Qingmei et al.). El primer caso reportado de infección por SARS-CoV data de noviembre de 2002 en la provincia China de Guangdong, donde en los siguientes siete meses, la epidemia de 
SARS-CoV resultó en más de 8000 casos reportados en 37 países y con una tasa de mortalidad de 9,6 \%. En 2012, fue reportada la infección por MERS-CoV en pacientes que desarrollaron neumonía aguda e insuficiencia renal en Arabia Saudita. En 2015 se produjo un brote secundario relativamente grande con 186 casos confirmados en Corea del Sur y hasta enero de 2020, se notificaron más de 2500 casos confirmados por laboratorio. con una tasa de mortalidad de $34,4 \%$ (Sin-Yee et al.). SARS-CoV-2 presenta una similitud genómica de un $79 \%$ con SARS-CoV y de un $50 \%$ con MERS-CoV. Si bien, SARS-CoV-2 es más transmisible en comparación con ambos (debido principalmente a la gran cantidad de pacientes asintomáticos infectantes), SARS-CoV-2 aparentemente es menos patogénico, ya que, tiene una tasa de mortalidad promedio de 3,8 \% (Zi-Wei et al.; Dae-Gyun et al.).

\section{BASES GENÉTICAS Y MOLECULARES DE SARS- CoV-2}

Morfología y Estructura Molecular de SARS-CoV-2. Mediante imágenes de microscopía electrónica de transmisión, la apariencia que tiene la partícula vírica o virión de SARS-CoV-2 es la de una corona solar (de allí el nombre de coronavirus). Esta partícula vírica presenta una morfología esférica de un diámetro que varía entre 60 a $140[\mathrm{~nm}]$ junto con espigas o "Spikes" de 8 a 12 [nm] de longitud aproximadamente (Jun, 2020). La estructura del virión consiste principalmente en una nucleocápside (que protege al material genético viral) y en una envoltura externa. En la nucleocápside, el genoma viral está asociado con la proteína de la nucleocápside $(\mathrm{N})$, la cual, se halla fosforilada e insertada dentro de la bicapa de fosfolípidos de la envoltura externa. En cuanto a la envoltura externa, allí se encuentran proteínas estructurales principales denominadas proteína Spike (S), proteína de membrana (M) y proteína de envoltura $(\mathrm{E})$, además, de proteínas accesorias, tales como, la proteína hemaglutinina esterasa $(\mathrm{HE})$, proteína 3, proteína $7 \mathrm{a}$, entre otras ( $\mathrm{Li}$ et al., 2020a,b; Mousavizadeh \& Ghasemi; Ali et al.). Entre las funciones de las proteínas estructurales principales están: La proteína (S) facilita la unión del virus al receptor de la célula huésped, la proteína $(M)$ ayuda a mantener la curvatura de la membrana y la unión con la nucleocápside, la proteína (E) juega un papel importante en el ensamblaje y liberación del virus y la proteína (N) forma parte de la nucleocápside al unirse al material genético viral. La proteína accesoria (HE) se halla solo en algunos Betacoronavirus y su actividad esterasa facilita la entrada del virus en la célula huésped, además, de ayudar en la su propagación (Ali et al.) (Fig. 1).

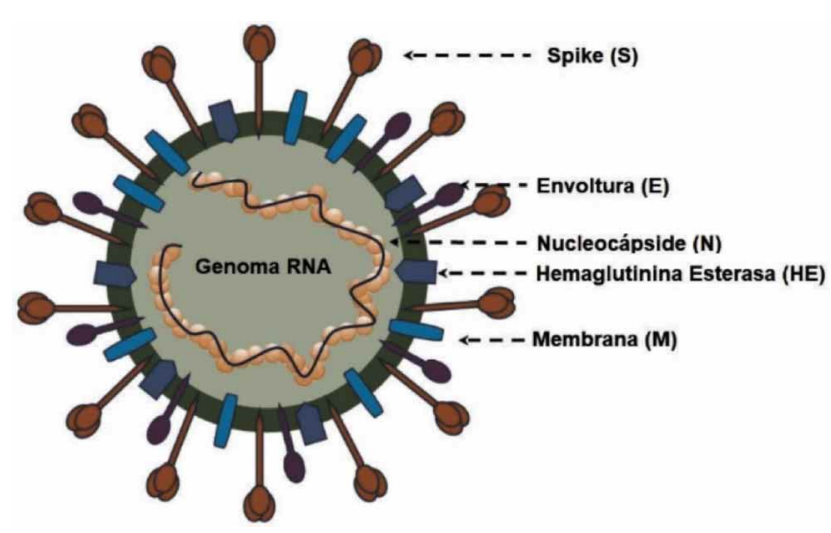

Fig. 1. Forma y estructura del virión de SARS-CoV-2. Partícula vírica de SARS-CoV-2 que posee una nucleocápside compuesta por RNA genómico asociado a la proteína $(\mathrm{N})$, cubierto por una envoltura externa de proteínas estructurales principales (S), (M) y (E) y proteínas accesorias como (HE). (Adaptado de Yuefei et al.).

\section{Estructura Genética de SARS-CoV-2}

El genoma de SARS-CoV-2 está formado por una única cadena de RNA monocatenario de polaridad positiva (+ssRNA) de aproximadamente 30.000 pares de bases. Esta cadena de RNA se asemeja, estructuralmente a un RNA mensajero (RNAm) de células eucarióticas, ya que, presenta un capuchón metilado (cap) en el extremo 5' y una cola poliadenilada (poli-A) en el extremo 3', lo que le da un gran parecido a los RNAm de la célula huésped. Sin embargo, a diferencia de los RNAm eucarióticos, este genoma viral contiene al menos seis marcos abiertos de lectura (ORF) (Mousavizadeh \& Ghasemi; Ali et al.; Li et al., 2020a,b). El genoma de SARSCoV-2 se puede dividir en tres tercios. Los dos primeros tercios (más cerca del extremo $5^{\prime}$ ) codifican para el gen de la replicasa viral. Este gen está constituido por dos ORF (ORF 1a y ORF 1b) (Mousavizadeh \& Ghasemi), los que, al comienzo de la infección, serán traducidos directamente en dos poliproteínas de gran tamaño llamadas pp1a y pp1ab. Estas poliproteínas posteriormente serán procesadas proteolíticamente para generar 16 proteínas no estructurales (nsps), las cuales estarán implicadas en la replicación del genoma viral y en la transcripción de RNAm subgenómicos (sgRNAs) (Rokni et al.; DaeGyun et al.; Chen et al.; Qingmei et al.). El último tercio del genoma (más cerca del extremo 3 ') codifica los genes de las 4 proteínas estructurales principales (proteína $(\mathrm{S})$, proteína $(\mathrm{M})$, proteína $(\mathrm{E})$ y proteína $(\mathrm{N})$ ) y lo genes de las proteínas accesorias (proteína ( $\mathrm{HE}), 3,7 \mathrm{a}$, entre otras) (Mousavizadeh \& Ghasemi). (Fig. 2). 


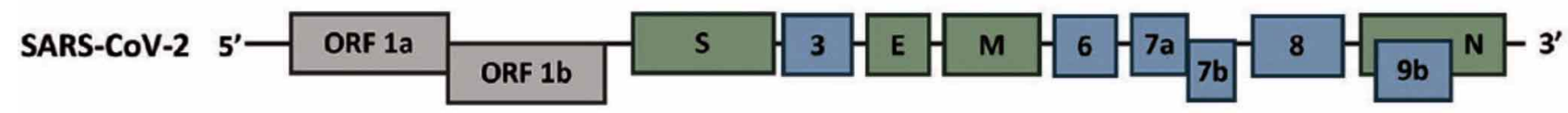

Fig. 2. Organización genética de SARS-CoV-2. Esquema del genoma RNA monocatenario de polaridad positiva (+ssRNA) de SARS-CoV-2. Hacia el extremo 5', se codifica el gen de la replicasa viral por medio de ORF 1a y ORF 1b para la traducción de las poliproteínas pp1a y pp1ab. Hacia el extremo 3', se codifican los genes de las 4 proteínas estructurales principales (S), (M), (E) y (N) (en verde) y las de las proteínas accesorias (en azul). (Adaptado de Sin-Yee et al.).

\section{MECANISMOS DE PATOGÉNESIS DE SARS-CoV-2}

Ingreso de SARS-CoV-2 en la Célula Huésped. Para que se inicie la infección en la célula huésped, es necesario que el virus se una a un receptor de la superficie celular. En SARS-CoV-2, esta unión se da entre la proteína $(S)$ del virus y el receptor de la enzima convertidora de la angiotensina 2 (ACE2). Esta unión da cuenta de la especificidad y del tropismo del virus hacia un tejido en particular (Mousavizadeh \& Ghasemi). ACE2 contribuye en la regulación de la presión arterial al realizar la conversión de la angiotensina I en angiotensina (1-9) (Yuefei et al.). El receptor de ACE2 se halla expresado en el tracto respiratorio bajo, corazón, riñón, estómago, vejiga, esófago e intestino (Yuefei et al.; Yan-Rong et al.). En el pulmón, se expresa principalmente en un subconjunto pequeño de células llamadas células alveolares tipo 2 (Eakachai et al.); y en la cavidad oral, está altamente expresado en células epiteliales de la lengua (Hao et al., 2020). La proteína (S) de SARS-CoV-2 posee dos subunidades (S1 y S2). La subunidad $\mathrm{S} 1$ es la que interacciona y se une al receptor ACE2 por medio del dominio de unión al receptor (RBD), mientras que, la subunidad S2 determina la fusión de la membrana del virus con la de la célula huésped (Yan-Rong et al.; Hao et al.). Para que el virus complete la entrada en la célula hospedera, la proteína (S) debe ser cortada o escindida por una enzima proteasa (TMPRRS2). La escisión de la proteína (S) ocurre en 2 diferentes posiciones de la subunidad S2, esto contribuye a la separación de la unión $\mathrm{RBD}$ de la subunidad $\mathrm{S} 1$ con el receptor ACE2 y a la posterior fusión de las membranas, facilitándose así, la entrada del virus mediante endocitosis (Ali et al.; Mousavizadeh \& Ghasemi).

Traducción del Genoma Viral y Transcripción de las Proteínas de SARS-CoV-2.Una vez completado el ingreso al citoplasma, la nucleocápside del virus se libera y permite la salida del RNA genómico viral. Esta secuencia de RNA actúa como un RNAm donde se transcribe directamente el gen de la replicasa viral (hacia el extremo 5') por medio de ORF 1a y ORF 1ab, traduciéndose en las poliproteínas pp1a y pp1ab (Mousavizadeh \& Ghasemi). Posteriormente, pp1a y pp1ab son procesadas proteolíticamente por enzimas proteasas como quimiotripsina codificada viralmente (3CLpro), proteasa principal (Mpro) y una o dos proteasas similares a la papaína (Chen et al.), lo que da lugar a la producción de las 16 proteínas no estructurales (nsps) designadas nsp1 a nsp16 (Sin-Yee et al.). Estas proteínas son necesarias para formar el llamado complejo replicasa transcriptasa (RTC), el cual, es ensamblado en vesículas de doble membrana originadas a partir del retículo endoplasmático (RE) (YanRong et al.; Mousavizadeh \& Ghasemi). La mayoría de las nsps están implicadas en la replicación y transcripción genómica del virus ejerciendo actividades enzimáticas de tipo proteasa, RNA polimerasa dependiente de RNA (RdRp), helicasa, exorribonucleasa, endorribonucleasa y metiltransferasa (Rokni et al.; Dae-Gyun et al.; Chen et al.; Qingmei et al.). Sin embargo, las funciones de algunas de ellas como nsp6, nsp7 y nsp8 son desconocidas. Se cree que podrían tener una función de desregulación de la respuesta inmune (Chen et al.). Finalmente, el complejo (RTC) replica y sintetiza un conjunto de RNAm subgenómicos (sgRNA) (Rokni et al.; Dae-Gyun et al.; Chen et al.; Qingmei et al.), que codifican para la elaboración de las proteínas estructurales principales (S), (M), (E), (N) y para las proteínas accesorias (hacia el extremo 3') (Yan-Rong et al.; Mousavizadeh \& Ghasemi).

Replicación del RNA, Ensamblaje de las Proteínas y Salida de SARS-CoV-2 de la Célula Huésped. En la replicación de los CoV como SARS-CoV-2, el RNA monocatenario de polaridad positiva (+ssRNA) sirve de molde para sintetizar, inicialmente, una copia a de RNA monocatenario de polaridad negativa (-ssRNA) (Li et al., 2020a,b). A partir de esta copia de -ssRNA, se producirán las poliproteínas pp1a y pp1ab, las cuales, se procesarán y conformarán el complejo RTC (Rokni et al.; Yan-Rong et al.; Mousavizadeh \& Ghasemi). El complejo RTC, gracias a su actividad enzimática replicativa, crea nuevamente una copia del genoma +ssRNA original del virus a partir del molde 
de -ssRNA. El RNA genómico viral recientemente sintetizado, se asocia con la proteína $(\mathrm{N})$ formando la nucleocápside. Las proteínas estructurales (S), (M) y (E); y las proteínas accesorias, expresadas a partir de los sgRNA, son elaboradas en las membranas del retículo endoplasmático (RE) y posteriormente trasportadas al complejo de Golgi donde serán ensambladas junto con la nucleocápside para producir nuevas partículas víricas, las que serán exportadas hacia la membrana plasmática celular en forma de vesículas, produciéndose así la liberación del virus (Yan-Rong et al.).

\section{RESPUESTA INMUNE FRENTE A SARS-CoV-2}

Respuesta Inmune Innata. Para montar una respuesta antiviral, el sistema inmune innato detecta una infección mediante receptores de reconocimiento de patrones (PRRs), es decir, receptores que identifican moléculas intrínsecas presentes en los patógenos. Estas moléculas intrínsecas corresponden a los pa-

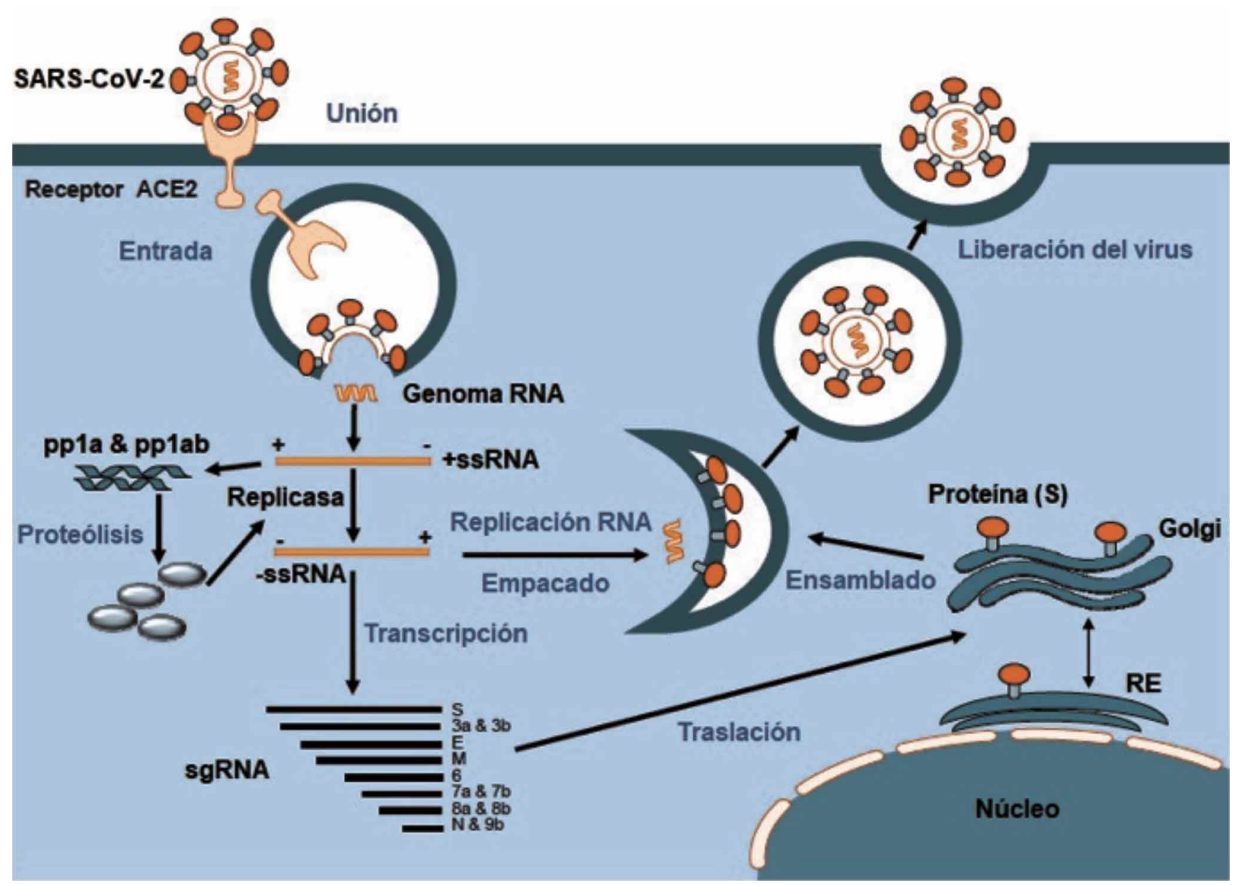

Fig. 3. Mecanismo de patogénesis de SARS-CoV-2. La infección por SARS-CoV-2 comienza con la unión de la proteína (S) con el receptor ACE2 de la célula huésped. El virión ingresa vía endocitosis y, posteriormente, el RNA genómico viral se libera al citoplasma y se traduce directamente en las poliproteínas pp1a y pp1ab que sufrirán proteólisis enzimática para generar las 16 proteínas (nsps) del complejo RTC. El complejo RTC, replica y sintetiza un conjunto de (sgRNA) que codifican para la producción de las proteínas estructurales principales (S), (M), (E) y (N); y las proteínas accesorias. Todas estas proteínas, junto con la nucleocápside, serán ensambladas a nivel del complejo de Golgi para formar las nuevas partículas víricas y así, finalmente, ser liberadas de la célula infectada. (Adaptado de Zhu et al., 2013). trones moleculares asociados a patógenos (PAMPs) (Li et al., 2020a,b; Rokni et al.). Entre los receptores PPR conocidos en la actualidad, se incluyen principalmente los receptores tipo toll (TLR). Estos receptores corresponden a proteínas transmembrana que presentan dos dominios, un dominio exterior que se une a PAMP y un dominio interior que inicia las vías o cascadas de señalización, induciendo diferentes respuestas biológicas (Li et al., 2020a,b). Entre los PAMPs que son reconocidos por los receptores TRL se incluyen lípidos, lipoproteínas, proteínas y ácidos nucleicos de virus, bacterias, parásitos y hongos ( $\mathrm{Li}$ et al., 2020a,b; Rokni et al.). En el caso de los CoV, se sabe que sus PAMPs están asociados su RNA (Rokni et al.). Cuando la proteína (S) de los CoV se une al receptor ACE2 de la célula huésped y se fusiona con membrana celular, se forma un endosoma donde el virus ingresa junto con su RNA. Los PAMPs asociados a este RNA son reconocidos por receptores tipo toll presentes en endosomas como TLR3, TLR7, TLR8 y TLR9 (Yan-Rong et al.; Rokni et al.). Este evento de reconocimiento lleva a la activación de varias vías de señalización y de factores de transcripción, como el factor nuclear kappa B (NF$k B)$, proteína activadora (AP-1), factor de regulador del interferón 3 (IRF3) y factor regulador del interferón 7 (IRF7) con su consecuente translocación nuclear. NFkB y AP-1 estimulan la expresión de genes que codifican muchas de las proteínas necesarias para la inflamación, tales como, factor de necrosis tumoral (TNF), citoquinas (IL-1, IL-6 e IL-12) y quimioquinas (CCL2 y CXCL8) (Rokni et al.). IRF3 e IRF7 promueven la producción de interferón tipo I (INF-a e INF-b) los que son importantes frente a las respuestas antivi-rales, ya que, son capaces de suprimir la replicación y diseminación viral en etapas tempranas $y$, además, inducir una respuesta inmune adaptativa efectiva (Rokni et al.; Eakachai et al.; Yan-Rong et al.). 
Respuesta Inmune Humoral. La respuesta inmune humoral juega un importante papel protector en las fases posteriores a la infección, especialmente con la producción de anticuerpos, evitando así una reinfección futura (Rokni et al.). La respuesta inmune mediada por linfocitos $T$ es esencial en la inmunidad adaptativa frente a las infecciones virales (Eakachai et al.). El microambiente de citoquinas generado por las células presentadoras de antígenos, como las células dendríticas, dicta la dirección del tipo de respuesta de los linfocitos T. Los tipos de respuestas generadas por los linfocitos $T$ son: Linfocitos $T$ helper (CD4+), que organizan la respuesta adaptativa activando a los linfocitos B en la producción de anticuerpos y linfocitos T citotóxicos (CD8+) que son esenciales para matar a las células infectadas por el virus (Eakachai et al.; Rokni et al.). En el caso de la epidemia de SARS-CoV del año 2002, los epítopos o determinantes antigénicos para los linfocitos $T$ y $B$ se establecieron para las proteínas estructurales del virus, es decir, las proteínas (S), (N), (M) y (E) (Eakachai et al.). Aunque aún es muy limitado el conocimiento sobre respuesta humoral en SARS-CoV-2, la evidencia muestra que las respuestas específicas de los linfocitos T son importantes para el reconocimiento de SARS-CoV-2 y a su vez, en la destrucción de las células infectadas, particularmente, en los pulmones de los individuos infectados (Rokni et al.). Los resultados de un estudio con 128 casos mostraron que el número y función de los linfocitos T citotóxicos (CD8+) fueron mayores que las respuestas de los linfocitos Thelper (CD4+) (Eakachai et al.; Rokni et al.). Respecto a los anticuerpos producidos por los linfocitos B, la inmunoglobulina M (IgM) se produce cuando la infección es más incipiente, mientras que, la inmunoglobulina $\mathrm{G}(\mathrm{IgG})$ se produce en etapas más tardías. Se han reportado limitados detalles serológicos de los anticuerpos frente a la infección por SARS-CoV-2. Sin embargo, en un estudio preliminar, se mostró, que después del inicio de la enfermedad, se obtuvo un peak para IgM al 9no día, mientras que, para IgG se obtuvo un peak en la 2da semana (Eakachai et al.). Además, se ha reportado que SARSCoV-2 induce producción de lgG contra la proteína $(\mathrm{N})$, la que puede ser detectada en el suero a los 14 días después del inicio de la enfermedad (Rokni et al.).

\section{DISCUSIÓN}

La enfermedad de COVID19 ha planteado un complejo escenario a nivel mundial en aspectos sanitarios, sociales y económicos. Se ha provocado una gran expansión global y un gran número de personas contagiadas debido a la alta transmisibilidad del virus que, si bien, en la mayoría de estas personas los síntomas son leves, no es menor la cantidad de personas que pueden agravarse, y así, poner en jaque los sistemas de salud asistenciales del mundo. Todas las áreas de la sociedad se ven afectadas y particularmente el área de la salud, donde los odontólogos se ven especialmente expuestos a los agentes virales, ya que, su nicho laboral implica el contacto directo con las fuentes o vías de transmisión. Por consiguiente, ante esta nueva perspectiva, las ciencias básicas juegan un rol muy importante y relevante en el control de la mitigación del virus. El conocimiento y comprensión de las bases biológicas, genéticas y moleculares de SARS-CoV-2 permite visualizar la posibilidad de establecer agentes farmacológicos o la generación de vacunas que puedan ayudar a combatir y disminuir los efectos patogénicos de la enfermedad. El bloqueo por medio de nuevos fármacos a las proteínas y mecanismos esenciales del proceso infectivo y replicativo de SARS-CoV-2 podría intuir el desarrollo de tratamientos contra este. De la misma manera, el establecer como determinantes antigénicos a las proteínas estructurales principales (S), (M), (E), y $(N)$ y accesorias de SARS-CoV-2 podría ayudar, a modo de vacuna, en la producción de anticuerpos por parte de los linfocitos $B$, mediados por linfocitos T. Por lo tanto, de acuerdo con la situación mundial, la investigación en el campo de las ciencias biomédicas se torna desafiante ante un mundo que solicita un desarrollo rápido y eficaz de un tratamiento contra la enfermedad de COVID-19.

AGRADECIMIENTOS. Escuela de Odontología. Facultad de Ciencias Universidad Mayor, sede Santiago. Chile.

PASTRIAN, S. G. Bases genéticas y moleculares del COVID-19 (SARS-CoV-2). Mecanismos de patogénesis y de respuesta inmune. Int. J. Odontostomat.,14(3):331-337, 2020.

ABSTRACT: In late December 2019, a new coronavirus (SARS-CoV-2) was identified as a causative agent of a new respiratory disease called COVID-19 by WHO. Its symptoms include fever, dry cough, and shortness of breath. Generally, these symptoms are mild, although, can be fatal in older adults and patients with comorbidities. A bibliographic search was carried out in Pubmed and Clinical Key. 22 articles were selected according to inclusion criteria. SARS-CoV-2 belongs to the genus of Betacoronaviruses and has genomic similarities to SARS-CoV and MERS-CoV. 
SARS-CoV-2 virion is made up of a nucleocapsid and external envelope composed of main structural and accesory proteins. Its genetic is a positive sense single stranded RNA in which important proteins are encoded for their transcription and replication. The mechanism of SARS-CoV-2 infection begins with the binding of the virion to (ACE2) receptor of the host cell and subsequent entry by endocytosis. This RNA genome is released into cytoplasm and the necessary proteins for the production of structural proteins and the replication of genetic material are transcribed and translated. Then, the replicated RNA associates with the nucleocapsid and assembles together with the structural proteins to form the viral particles that will be released from the infected cell. The immune system faces viral infection through the recognition of molecular patterns associated with pathogens (PAMPs) by innate immunity and the action of $T$ cells and $B$ cells by humoral immunity. Knowledge of the genetic and molecular basis of SARS-CoV-2 allows us to visualize the possibility of establishing pharmacological or vaccine treatments to control and reduce the pathogenic effects of the disease.

KEY WORDS: COVID-19, SARS-CoV-2, Genetic, Pathogenesis, Inmune response.

\section{REFERENCIAS BIBLIOGRÁFICAS}

Ali, R.; Shamsah, A.; Shafiul, H.; Ranjit, S.; Ruchi, T.; Yashpal, M.; Kuldeep, D.; Iqbal, Y.; Bonilla-Aldana, K. \& Rodríguez-Morales, A. SARS-CoV-2, SARS-CoV, and MERS-CoV: a comparative overview. Infez. Med., 2:174-84, 2020.

Chen, Y.; Liu, Q. \& Guo, D. Emerging coronaviruses: Genome structure, replication, and pathogenesis. J. Med. Virol., 92:41823, 2020.

Dae-Gyun, A.; Hye-Jin, S.; Mi-Hwa, K.; Sunhee, L.; Hae-Soo, K.; Jinjong, M.; Bum-Tae, K. \& Seong-Jun, K. Current Status of Epidemiology, Diagnosis, Therapeutics, and Vaccines for Novel Coronavirus Disease 2019 (COVID-19). J. Microbiol. Biotechnol., 30(3):313-24, 2020.

Eakachai, P.; Chutitorn, K. \& Tanapat, P. Immune responses in COVID-19 and potential vaccines: Lessons learned from SARS and MERS epidemic. Asian Pac. J. Allergy Immunol., 38:1-9, 2020.

Firas, R.; Mazhar, A.; Ghena, K.; Dunia, S. \& Amjad, A. SARS-CoV2 and Coronavirus Disease 2019: What we know so far. Pathogens., 9:231, 2020.

Hao, X.; Liang, Z.; Jiaxin, D.; Jiakuan, P.; Hongxia, D.; Xin, Z.; Taiwen, L. \& Qianming, Chen. High expression of ACE2 receptor of 2019$\mathrm{nCoV}$ on the epithelial cells of oral mucosa. Int. J. Oral Sci., 12:8, 2020.

Hussin, R. \& Siddappa, B. The epidemiology and pathogenesis of coronavirus disease (COVID-19) outbreak. J. Autoimmun., 109:102433, 2020.

Jun Z. SARS-CoV-2: an Emerging Coronavirus that Causes a Global Threat. Int. J. Biol. Sci., 16(10):1678-85, 2020.

Kannan, S.; Shaik, P.; Sheeza, A. \& Hemalatha, K. COVID-19 (Novel Coronavirus 2019) - recent trends. Eur. Rev. Med. Pharmacol. Sci., 24:2006-11, 2020.

Li, G.; Fan, Y.; Lai, Y.; Han, T.; Li, Z.; Zhou, P.; Pan, P.; Wang, W.; Hua D.; Liu, X.; Zhang, Q. \& Wu, J. Coronavirus infections and immune responses. J. Med. Virol., 92(4):424-32, 2020.
Liu, J.; Zheng, X.; Tong, Q.; Li, W.; Wang, B.; Sutter, K.; Trilling, M.; Lu, M.; Dittmer, U. \& Yang, D. Overlapping and discrete aspects of the pathology and pathogenesis of the emerging human pathogenic coronaviruses SARS-CoV, MERS-CoV, and 2019nCoV. J. Med. Virol., 92:491-4, 2020.

Mahdi, A.; Parham, M.; Ehsaneh, K.; Sükran, K.; Esposito, I.; Khudaverdi, G.; Sounkalo, D.; Esposito, S.; Tuba, D.; Elham, Z. \& Hossein, S. Clinical manifestation, diagnosis, prevention and control of SARS-CoV-2 (COVID-19) during the outbreak period. Infez. Med., 2:153-65, 2020.

Mousavizadeh, L. \& Ghasemi, S. Genotype and phenotype of COVID-19: Their roles in pathogenesis. Mousavizadeh L, Ghasemi S, Genotype and phenotype of COVID-19: Their roles in pathogenesis. J. Microbiol. Immunol. Infec., 2020. DOI: https:/ /www.doi.org/10.1016/j.jmii.2020.03.022

Qingmei, H.; Qingqing, L.; Shenhe J. \& Liangshun, Y. Coronavirus 2019-nCoV: A brief perspective from the front line. J. Infect., 80:373-7, 2020.

Rokni, M.; Ghasemi, V. \& Tavakoli, Z. Immune responses and pathogenesis of SARS-CoV-2 during an outbreak in Iran: Comparison with SARS and MERS. Rev. Med. Virol., 1-6, 2020.

Sin-Yee, F.; Kit-San, Y.; Zi-Wei, Y.; Chi-Ping, C. \& Dong-Yan, J. A tug-of-war between severe acute respiratory syndrome coronavirus 2 and host antiviral defence: lessons from other pathogenic viruses. Emerg. Microb. Infect., 9:1558-70, 2020.

World Health Organization (WHO). Coronavirus disease 2019 (COVID-19) Situation Report - 98. Ginebra, World Health Organization, 2020. Disponible en: https://www.who.int/docs/ default-source/coronaviruse/situation-reports/20200427-sitrep98-covid-19.pdf?sfvrsn=90323472 4

Li, X.; Geng, M; Peng, Y.; Meng, Y. \& Lu, S. Molecular immune pathogenesis and diagnosis of COVID-19. X. Li et al., Molecular immune pathogenesis and diagnosis of COVID-19, J. Pharm. Anal., 2020. DOl: https://www.doi.org/10.1016/

Xiaoyi, H.; Fengxiang, W.; Liang, H.; Lijuan, W. \& Ken, C. Epidemiology and Clinical Characteristics of COVID-19. Arch. Iran Med., 23(4):268-71, 2020.

Yan-Rong, G.; Qing-Dong, C.; Zhong-Si, H.; Yuan-Yang, T.; ShouDeng, C.; Hong-Jun, J.; Kai-Sen, T.; De-Yun, W. \& Yan, Y. The origin, transmission and clinical therapies on coronavirus disease 2019 (COVID 19) outbreak - an update on the status. Mil. Med. Res., 7:11, 2020.

Yuefei, J.; Haiyan, Y.; Wangquan, J.; Weidong, W.; Shuaiyin, C.; Weiguo, Z. \& Guangcai, D. Virology, Epidemiology, Pathogenesis, and Control of COVID-19. Viruses, 12:372, 2020.

Zhu, X.; Liu, Q.; Du, L. \& Jiang, S. Receptor-binding domain as a target for developing severe acute respiratory syndrome vaccines. J. Thorac. Dis., 5(S2):S142-S8, 2013.

Zi-Wei, Y.; Shuofeng, Y.; Kit-San, Y.; Sin-Yee, F.; Chi-Ping, C. \& DongYan, J. Zoonotic origins of human coronaviruses. Int. J. Biol. Sci., 16(10):1686-97, 2020.

Dirección para correspondencia:

Gabriel Pastrian Soto.

Cirujano Dentista

Cobija 2191 oficina 404-A

Calama - CHILE

Email: gabriel.pastrians1@mayor.cl

Recibido : 27-4-2020

Aceptado: $28-4-2020$ 